\title{
PENSIÓN DE VIUDEDAD, MATRIMONIO GITANO Y PAREJAS DE HECHO
}

\section{WIDOW'S PENSION, GYPSY MARRIAGE AND DEBAL COUPLES}

\section{Manuel Martín Hernández-Carrillo}

Magistrado Especialista de lo Social

Presidente de la Sala de lo Social

Tribunal Superior de Justicia de Andalucía/ Málaga

m.martin@poderjudicial.es

Recepción de trabajo: 31-08-2021 - Aceptación: 05-09-2021

1. INTRODUCCIÓN. — 2. LA SENTENCIA DEL TEDH EN EL CASO “LA NENA". — 3. DOCTRINA DEL TRIBUNAL CONSTITUCIONAL. SENTENCIA 1/2021. * 4. PERPECTIVA DEL MATRIMONIO GITANO DESDE LA ÓPTICA DE LAS PAREJAS DE HECHO A EFECTOS DE LA PENSIÓN DE VIUDEDAD. $\square$ 5. CONCLUSIONES 
PENSIÓN DE VIUDEDAD, MATRIMONIO GITANO Y PAREJAS DE HECHO

\section{RESUMEN}

Es doctrina judicial constante la de que las uniones por el rito gitano no producen efectos civiles y, por ende, no generan derecho a la pensión de viudedad al fallecimiento de uno de sus integrantes. Con la excepción de la sentencia del TEDH de 2009, asunto Muñoz Díaz c. España (conocido como "La Nena"), por las particularidades que concurrían, basadas en la buena fe de los contrayentes y la expectativa razonable creada por las autoridades del Estado español, el TS y el TC siguen negando el acceso a la pensión de viudedad, incluso en supuestos en los que el fallecimiento del causante se produjo después de la Ley 40/2007, que por primera vez posibilitaba el acceso a la pensión de viudedad al integrante supérstite de dichas parejas. El voto particular publicado junto a la sentencia del TS de 25 de enero de 2.018, Recurso $2401 / 2016$, razona sobre lo innecesario de dicho requisito a las uniones celebradas conforme a los usos y costumbres gitanos por las particularidades de dicha cultura, fuerte arraigo familiar y unidad matrimonial no cuestionada.

PALABRAS CLAVE: matrimonio gitano, pensión de viudedad, parejas de hecho, discriminación indirecta.

\section{ABSTRACT}

It is a constant judicial doctrine that unions by the gypsy rite do not produce civil effects and, therefore, do not generate the right to a widow's pension upon the death of one of its members. With the exception of the 2009 ECHR ruling, Muñoz Díaz v. Spain (known as "La Nena"), due to the particularities that concurred, based on the good faith of the contracting parties and the reasonable expectation created by the authorities of the Spanish State, the Supreme Court and the TC continue to deny access to the widow's pension, even in cases in which the deceased's death occurred after Law 40/2007, which for the first time made it possible for the surviving member of said couples to access the widow's pension. The particular vote published together with the judgment of the Supreme Court of January 25, 2.018, Appeal 2401/2016, reasons about the unnecessary of said requirement to unions celebrated in accordance with the uses and gypsy customs due to the particularities of said culture, strong family roots and unquestioned marital unity.

KEYWORDS: gypsy marriage, widow's pension, domestic partnership, indirect discrimination. 


\section{INTRODUCCIÓN}

Es doctrina judicial constante, tanto del Tribunal Supremo como del Tribunal Constitucional (por todas, reciente sentencia núm. 1/2021 de 25 de enero, dictada por la Sala segunda) la que proclama que las uniones celebradas por el rito gitano no generan para el integrante supérstite pensión de viudedad. Se trata de una cuestión de indudable interés en tanto que el principio de no discriminación por razón de etnia/minoría, unido al de no discriminación por razón de sexo (discriminación múltiple, o mejor, interseccional en atención a su resultado final) ha estado presente en las distintas resoluciones judiciales que han abordado la cuestión.

Debate al que habría que añadir la consideración, a los efectos que ahora se analizan, de si las uniones por el rito gitano, aún no inscritas debidamente, pueden generar derecho a la pensión de viudedad al equiparase a las parejas de hecho por las particularidades culturales de dicha etnia.

\section{LA SENTENCIA DEL TEDH EN EL CASO "LA NENA"}

Ya la sentencia del TEDH de 8 de diciembre de 2009, asunto Muñoz Díaz c. España (asunto conocido como "La Nena"), condenó a España al haberle negado a la demandante la pensión de viudedad a la muerte de quien había sido su "esposo" conforme al rito gitano. No obstante, el TEDH hizo pivotar su decisión, no ya sobre un posible trato discriminatorio por razón de pertenencia a determinada etnia/minoría (ni siquiera se llegó a plantear el debate sobre la eventual discriminación por razón de sexo) ni por atribuir al matrimonio gitano eficacia jurídica alguna, sino sobre la base del principio de la buena fe: porque la validez que le atribuye la comunidad romaní y el reconocimiento de la unión como «matrimonio» en determinados documentos oficiales habían generado en la contrayente comprensible buena fe, una expectativa razonable creada por el propio Estado de acceder a la pensión de viudedad. En muy apretada síntesis, la demandante se casó en el año 1971, con quince años de edad por el rito gitano, de cuya unión nacieron seis hijos, los cuales aparecían en la cartilla de la Seguridad Social, el Libro de Familia y en el reconocimiento de familia numerosa.

En definitiva, la sentencia del TEDH de 2009, tiene un muy restringido alcance a los efectos que ahora se analizan pues, si bien se afirma que la denegación a la demandante de la pensión de viudedad supuso una violación del principio de igualdad consagrado en el artículo 14 del CEDH, también proclama que el hecho de que el matrimonio gitano no tenga efectos civiles, no constituye una discriminación prohibida por el citado precepto del Convenio. 


\section{DOCTRINA DEL TRINUNAL CONSTITUCIONAL. SENTENCIA $1 / 2021$}

En el supuesto analizado por el Tribunal Constitucional en su sentencia núm. 1/2021 de 25 de enero, dicho Tribunal considera que no es de aplicación la expresada doctrina del TEDH de 2009 en tanto que no concurre la presunción de buena fe puesto que la recurrente en amparo "era plenamente conocedora de la falta de validez de su matrimonio, al haberse celebrado por un rito no reconocido por nuestro ordenamiento jurídico y tampoco formalizó en momento alguno su relación more uxorio en el modo exigido por la legislación para el reconocimiento de su derecho a la prestación de viudedad por el sistema nacional de seguridad social".

La sentencia del Tribunal Constitucional trae causa de la demanda presentada por quien contrajo matrimonio por los usos y costumbres gitanos en 1974, habiendo fallecido el causante el 27 de abril de 2014, no formalizándose en ningún momento como pareja de hecho, no constar en ningún documento oficial la condición de matrimonio de la pareja y apareciendo en el libro de familia como "solteros". El Juzgado de lo Social de instancia desestimó la demanda, acogiendo la tesis de la Entidad Gestora (no haberse constituido como pareja de hecho con el fallecido al menos dos años antes del fallecimiento) y, recurrida en suplicación, el Tribunal Superior de Justicia, sobre la base de la sentencia antes citada del TEDH, estimó la demanda y le reconoció su derecho al percibo de la pensión de viudedad. Razonó el TSJ que "... no puede entenderse que de mala fe se fingieran como matrimonio gitano en su entorno familiar y social durante tanto tiempo para en su momento futuro cobrar una eventual pensión, por lo que de denegar la pensión se podría producir una discriminación por razones étnicas y culturales". El INSS recurrió en casación para la unificación de doctrina ante el TS, que terminó estimando el recurso, casando la sentencia de suplicación y absolviendo a la Entidad Gestora de la pretensión de la demandante.

Es en el marco descrito donde se plantea el recurso de amparo que ha sido finalmente desestimado por el TC en la sentencia de 25 de enero de 2021.

Los argumentos del Tribunal Supremo (sentencia de 25 de enero de 2.018, Recurso 2401/2016) para estimar el recurso y terminar denegando la pensión de viudedad a la solicitante, inaplicando la doctrina del TEDH de 2009, se sustentan, en primer lugar, porque en aquel supuesto se produjo una situación de buena fe y expectativa razonable de derecho creada por las autoridades españolas, a diferencia del supuesto que analiza la sentencia, en donde ningún documento oficial acredita la existencia de matrimonio y apareciendo los integrantes de la pareja como "solteros"; en segundo lugar, porque el propio TEDH no contradice la doctrina del TC contenida en la STC 69/2007, de 16 de abril, de que el principio de igualdad que proclama el art. 14 CE no alcanza a la llamada "discriminación por indiferenciación", al no consagrar un derecho subjetivo al trato normativo desigual; y en tercer lugar, porque la pertenencia de la demandante a una "minoría étnica no repercutía en la aplicación o en la interpretación de la normativa de que tratamos, sino tan sólo en la configuración de la buena fe". 
Merece destacarse el contundente razonamiento contenido en el fundamento de derecho tercero, en el que se afirma que atribuir a las uniones por los usos y costumbres gitanos los efectos pretendidos en materia de seguridad social, supondría tanto como considerar de peor condición a las parejas de hecho, las no registradas conforme a la normativa estatal o de las correspondientes Comunidades Autónomas, es decir, a las parejas que, "por razones ideológicas - tan respetables como las culturales- no se han constituido como pareja de hecho en la forma legalmente prescrita, y a los que - no infrecuentemente- les hemos negado la prestación de viudedad". Además, la merecedora protección de la minoría gitana no alcanza hasta el punto de "... excepcionar la aplicación de la ley en los múltiples aspectos en que pudiera reflejarse su diversidad étnico-cultural [matrimonio; familia; comportamiento social...], so pena de comprometer gravemente la seguridad jurídica y la uniformidad en la aplicación de aquélla —la ley-".

Dicha línea doctrinal ha sido seguida por el Tribunal Supremo en su sentencia de 24 de junio de 2020 (Recurso: 716/2018), en la que, además, resalta "la especial trascendencia que la propia STEDH concede al hecho de que en aquel asunto se había iniciado la convivencia bajo el rito gitano en el año 1971, con anterioridad a la vigencia de la Constitución, y cuando en España solo era posible casarse de acuerdo con el rito del derecho canónico de la Iglesia católica, excepto previa declaración de apostasía. Lo que lleva al Tribunal a afirmar que no se podía exigir a la demandante, sin vulnerar su derecho a la libertad religiosa, que se casara legalmente, es decir, según el derecho canónico en 1971, cuando manifestó su consentimiento para casarse según el rito gitano" (ap.57)". Pero tal argumento ha quedado totalmente superado, sigue razonado la sentencia "tras la promulgación del texto constitucional y de toda la normativa legal que admite la celebración del matrimonio en forma civil, o por cualquiera de los ritos de las diferentes confesiones que disponen de acuerdos con el Estado a tal efecto o han obtenido el reconocimiento de notorio arraigo, respetando absolutamente de esta forma el derecho a la libertad religiosa".

\section{PERPECTIVA DEL MATRIMONIO GITANO DESDE LA ÓPTICA DE LAS PAREJAS DE HECHO A EFECTOS DE LA PENSIÓN DE VIUDEDAD}

En este orden de cosas, parece interesante y merecedora de atención, la tesis mantenida en el voto particular formulado por la Magistrada Lourdes Arastey, al que se adhirió la magistrada María Luisa Segoviano, mediante el cual discrepan del parecer mayoritario de la Sala IV en un aspecto novedoso que se trae al debate, a saber, la consideración de los matrimonios celebrados por personas de la cultura gitana, conforme a sus usos y costumbres, como pareja de hecho a los fines de generar derecho al percibo de la pensión de viudedad al fallecimiento de uno de ellos. Y es que, razona el voto 


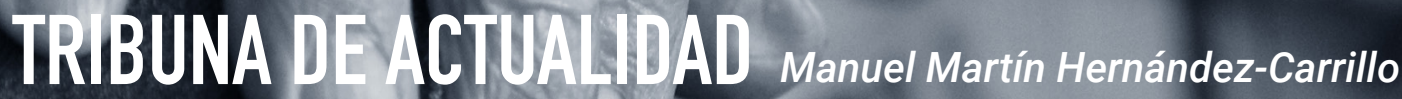

PENSIÓN DE VIUDEDAD, MATRIMONIO GITANO Y PAREJAS DE HECHO

particular, el caso analizado se diferencia de los hasta entonces resueltos en tanto que en "... la unión que dio lugar al dictado de la sentencia del TEDH de 2009, se trataba de una situación anterior a la Ley 40/2007 (el fallecimiento del causante se había producido en el año 2000), en la que, por primera vez en nuestro país, se reconoció el acceso a la pensión de viudedad de las parejas de hecho. Para el caso allí examinado la única vía de obtención de la pensión se encontraba en la equiparación de la situación de la solicitante con la del matrimonio".

Sin embargo, en el supuesto analizado no concurren las características que Ilevaron al TEDH al dictado de la sentencia estimatoria de la demanda al no concurrir los requisitos que hacían presumir la buena fe. Además, al fallecimiento del causante, ya estaba en vigor la Ley 40/2017 y el causante y su contrayente bien pudieron registrarse como pareja de hecho. Por tal razón, razona el voto particular, el núcleo de lo planteado radica en determinar la posibilidad o no del “... acceso a la pensión de viudedad como pareja de hecho por parte de quien ha estado unida al causante por virtud de aquel rito gitano y la interpretación que deba hacerse de lo dispuesto en el art. 174.3 LGSS aplicable al caso, según el cual la existencia de la pareja de hecho se acredita con la «inscripción en alguno de los registros específicos existentes en la comunidades autónomas o ayuntamiento del lugar de residencia»". Y concluye el voto particular en el sentido de que la exigencia de la inscripción puede comportar un trato peyorativo, como integrante de un concreto grupo étnico.

Después de recordar el voto particular la doctrina del TEDH sobre la discriminación indirecta ["ausencia de un trato diferencial para corregir una desigualdad, sin justificación objetiva y razonable, puede suponer la violación del principio de no discriminación (STEDH de 73 noviembre 2007, Asunto D.H. y otros v. República Checa)"] y la "historia turbulenta y su constante desarraigo", proclama que la minoría étnica gitana se han convertido en un colectivo especialmente desfavorecido y vulnerable, merecedor de protección especial en atención "a sus necesidades y a su estilo de vida diferente, tanto en el marco normativo pertinente como al llegar a decisiones en casos concretos (STEDH de 27 mayo 2004 Connors v. Reino Unido; y 9 enero 2013, Horváth y Kiss v. Hungría)".

De hecho, la STJUE de 16 julio 2015 (CHEZ Razpredelenie Bulgaria, C-83/14), interpretando la inclusión del pueblo gitano en el ámbito de protección de la Directiva 2000/43/CE del Consejo, de 29 de junio de 2000, señala que "el concepto de origen étnico, que proviene de la idea de que los grupos sociales se identifican en especial por una comunidad de nacionalidad, de fe religiosa, de lengua, de origen cultural y tradicional y de entorno de vida, se aplica a la comunidad gitana" (con cita de las STEDH de 6 julio 2005, Natchova y otros v. Bulgaria, 22 diciembre 2009, Sejdiæ y Finbci v. BosniaHerzegovina).

Resalta el voto particular "el fuerte arraigo de sus tradiciones y de la sólida estructuración de la comunidad gitana, intensamente ligada a la familia y al parentesco", por lo que llega a la conclusión de que tras la unión conforme al rito gitano propio de su cultura, con independencia de la ineficacia jurídica de aquel rito, acreditada indubitadamente la convivencia permanente desde ese momento hasta el fallecimiento del causante, "ninguna duda cabe que los convivientes gitanos sostienen la convicción de que su relación de pareja se desarrolla como si de un matrimonio se tratara". 
Y termina concluyendo que "exigir en estos casos que la existencia de la pareja de hecho se acredite por la inscripción del registro de parejas se torna claramente redundante y, por ende, innecesaria, en la medida en que para la pareja gitana la aceptación de la llamada <ley gitana> les convierte, a su entender y al del resto de la comunidad en la que desarrollan su vida, en una unidad matrimonial no cuestionada como tal y, si cabe, con más fuerza".

\section{CONCLUSIONES}

Parecen incuestionables los razonamientos del TC y TS en orden a la no atribución de efectos civiles a las uniones celebradas conforme a la cultura gitana, criterio que ha quedado incólume en la sentencia del TEDH de 8 de diciembre de 2009, asunto Muñoz Díaz c. España.

La "historia turbulenta y su constante desarraigo", que ha hecho del pueblo gitano una minoría especialmente desfavorecida y vulnerable, hace que deba dispensarse una protección especial en atención "a sus necesidades y a su estilo de vida diferente".

Si bien la regla del art. 221.3 del TRLGSS tiende a constatar la verdadera existencia de la pareja de hecho y sea lógico y justificado el establecimiento del requisito, "la especial realidad fáctica de este grupo étnico ofrece mayores garantías de que esa situación de pareja existe mientras perdura la convivencia entre sus dos componentes, superando en estos casos el test necesario de satisfacción de la finalidad buscada por dicha norma". 